\title{
Disseminated epidermolytic acanthoma probably related to trauma
}

\author{
I. Sánchez-Carpintero, A. España and M.A. Idoate*
}

Departments of Dermatology and *Pathology, University Clinic of Navarra, School of Medicine, University of Navarra, PO Box 4209, 31080 Pamplona, Navarra, Spain

\section{SUMMARY}

Epidermolytic acanthoma is a rare benign tumour, which may occur in both isolated and disseminated forms. Only seven cases of disseminated epidermolytic acanthoma (DEA) have been described. This entity should be distinguished from other hereditary or acquired conditions which involve epidermolytic hyperkeratosis and other benign acanthomas. On the basis of the clinical history and the histological findings, we diagnosed a case of DEA which was probably secondary to repeated trauma.

\section{KEY WORDS}

Disseminated epidermolytic acanthoma, epidermolytic acanthoma, repeated trauma, tumour

Correspondence: Dr Agustín España

E-mail: aespana@unav.es 
Epidermolytic hyperkeratosis $(\mathrm{EH})$ is a reactive histo-pathological pattern characterized by the presence of alterations in intracytoplasmic tonofilaments, with the formation of eosinophilic intracellular masses and preservation of desmosomes. ${ }^{1}$ It is associated with localized or widespread cutaneous diseases, of both an inherited and an acquired nature. Among the acquired disorders, disseminated epidermolytic acanthoma (DEA) is unusual. We present the case of a patient with DEA. The pathology studies performed show a primary disorder of the tonofilaments of the keratinocytes, leaving the desmosomes unaffected; the lesions were probably related to repeated local trauma.

\section{CASE REPORT}

A 36-year-old woman presented with multiple small asymptomatic lesions on the abdominal region and the thorax, which had developed over the previous 6 years. In recent months she had noticed that they had increased in number, but was unable to relate this to any triggering factor. She had also noted a deepening in pigmentation. She had no relevant personal history, was not taking any medication systematically, nor did she report any allergies to drugs. There was no family history of ichthyosiform processes. On physical exploration, she was found to have multiple keratotic popular lesions, 2-3 $\mathrm{mm}$ in diameter, which were brown in colour, and which were mainly located in a band around the abdomen, on the waistline (Fig. 1), with only a few scattered across the thorax. A biopsy from an abdominal lesion showed a well-defined area of orthokeratotic hyperkeratosis and focal acanthosis. The cells of the stratum granulosum and stratum spinosum had large clear perinuclear spaces, with dense masses of keratohyalin and condensation of the cytoplasm with an eosinophilic appearance, resembling inclusion bodies. There was a slight perivascular lymphocyte infiltrate. Electron microscopy revealed a generalized alteration of the tonofilaments, which formed electrondense masses in a perinuclear arrangement of two kinds: thick bundles of interwoven tonofilaments with partial loss of the fibrillar character, which were highly osmiophilic and mainly grouped in a perinuclear fashion; and large amorphous masses of variable size and irregular outline which were peripherally arranged. The keratinocytes seemed to be cohesive (Fig. 2). Frequent intracellular vacuoles were observed, and the desmosomes were preserved (Fig. 3). On the basis of the clinical history and the histological findings, we diagnosed DEA.

\section{DISCUSSION}

$\mathrm{EH}$ is thought to be a reactive histopathological pattern, the principal features of which were described by Acker-man: ${ }^{1}$ (i) perivascular vacuolization, of variable size, of the cells of the stratum spinosum and stratum granu-losum; (ii) the keratinocytes do not have well-defined limits, which gives the epidermis a reticulate appearance; (iii) an increase in the number of basophil bodies of a keratohyalin appearance, irregular in size and shape, and of eosinophilic bodies of a trichohyalin appearance, always the same 
thickness as the epidermis, but mainly in the granular layer, and not affecting the basal layer; and (iv) compact hyperkeratosis of the stratum corneum.

EH can appear in various clinical forms. Mostly, the hereditary nature and clinical picture in these disorders enable a precise diagnosis. There are also some non-hereditary disorders which may include $\mathrm{EH}$ as an occa-sional finding. ${ }^{2}$ This histological pattern can also be observed in other acquired EH forms as epidermolytic acanthoma. This is a benign acquired tumour of the epidermis which usually appears on the back in middleaged patients, and which takes the form of numerous flat, discrete, greyish-brown papules of 2- $6 \mathrm{~mm}$ in diameter. In 1970 Shapiro and Baraf ${ }^{3}$ described the first six patients with isolated epidermolytic acanthoma (IEA), and a seventh with multiple lesions on the scrotum. Subsequently two further cases were described of patients with lesions on the abdomen. ${ }^{4,5}$ The term DEA was first coined by Hirone and Fukushiro, ${ }^{6}$ in a patient with multiple lesions on the trunk, upper limbs and shoulders. Since then, six further cases have been described. ${ }^{2,7-11}$ Electron microscopy, in DEA and in most cases of $\mathrm{EH}$, demonstrates that the desmosomes are conserved and the mechanism of blister formation is cytolysis rather than acantholysis. ${ }^{6,7}$

DEA should also be distinguished from other benign acanthomas such as acantholytic acanthoma. ${ }^{12}$ In this skin tumour, the characteristic histological abnormality is the presence of acantholysis resulting from a rupture of the desmosomes. None of these findings occurs with DEA. ${ }^{13}$

The mechanisms involved in the development of DEA are not fully understood. It is known that under normal conditions, the basal cells of the epidermis synthesize keratins $\mathrm{K} 5$ and K14, and on some occasions K15 and K17. When the epidermis begins to be stratified and differentiated, the suprabasal keratinocytes begin to synthesize K1 and K10. ${ }^{14}$ In processes involving $\mathrm{EH}$, patients have a mutation in the genes responsible for the synthesis of $\mathrm{K} 1$ and $\mathrm{K} 10^{15}$ in the suprabasal cells. ${ }^{16}$ It could be that these alterations in $\mathrm{K} 1$ and K10 have a hereditary basis in some disorders which involve EH, but in acquired forms such as IEA or DEA they may be induced by an exogenous factor, such as ultraviolet light ${ }^{9,11}$ or viruses. ${ }^{17}$ We do not know if DEA may represent some postzygotic/mosaic abnormality of K1 or K10 or whether trauma is involved in these skin lesions. In our patient, tight clothes at the waistline, and perhaps small unnoticed traumas on the thorax, could have triggered DEA.

\section{REFERENCES}

1. Ackerman AB. Histopathologic concept of epidermolytic hyperkeratosis. Arch Dermatol 1970; 102: 253-9.

2. Knipper JE, Hud JA, Cockerell CJ. Disseminated epidermolytic acanthoma. Am J Dermatopathol 1993; 15: 70-2.

3. Shapiro L, Baraf CS. Isolated epidermolytic acanthoma. A solitary tumor showing granular degeneration. Arch Dermatol 1970; 101: 220-3. 
4. Saito F, Yamatsuta Y. Isolated epidermolytic acanthoma. Rinsho Derma 1971; 13: 749-54.

5. Tokuda A. Isolated epidermolytic acanthoma. Jpn J Clin Dermatol 1973; 27: 431-7.

6. Hirone T, Fukushiro R. Disseminated epidermolytic acanthoma. Acta Derm Venereol (Stockh) 1973; 53: 393-402.

7. Miyamoto I, Ueda K, Sato M, Yasuno H. Disseminated epidermolytic acanthoma. J Cutan Pathol 1979; 6: 272-9.

8. Nakagawa $T$, Nishimoto $M$, Takaiwa $T$. Disseminated epidermolytic acanthoma revealed by PUVA. Dermatológica 1986; 173: 150-3.

9. Chun SI, Lee JS, Kim NS, Park KA. Disseminated epidermolytic acanthoma with disseminated superficial porokeratosis and verruca vulgaris in an immunosuppressed patient. J Dermatol 1995; 22: 690-2.

10. Metzler G, Sonnichsen K. Disseminated epidermolytic acanthoma. Hautarzt 1997; 48: 740-2.

11. Shimizu H, Kimura S. Disseminated epidermolytic acanthoma. Rinsho Derm 1981; 35: 1061-5.

12. Brownstein MH. Acantholytic acanthoma. J Am Acad Dermatol 1988; 19: 783-6.

13. Megahed M, Scharffetter-Kochanek K. Acantholytic acanthoma. Am J Dermopathol 1993; 15: 283-5.

14. Morley SM, Lane EB. The keratinocyte cytoskeleton. In: The Keratinocyte Handbook (Leigh IM, Lane EB, Watt FM, eds), Cambridge: Cambridge University Press, 1994: 293-321.

15. Cheng J, Syder AJ, Yu QC et al. The genetic basis of epidermolytic hyperkeratosis: a disorder of differentiation-specific epidermal keratin genes. Cell 1992; 70: 811-19.

16. Ishida-Yamamoto A, McGrath JA, Judge MR et al. Selective involvement of keratins $\mathrm{K} 1 \mathrm{y} \mathrm{K} 10$ in the cytoskeletal abnormality of epidermolytic hyperkeratosis (bullous congenital icthyosiform erythroderma). J Invest Dermatol 1992; 99: 19-26.

17. Tomoda T, Sakazaki Y, Ono T. A case of isolated epidermolytic acanthoma in which virus-like particles were observed. Jpn J Dermatol 1983; 93: 152732. 


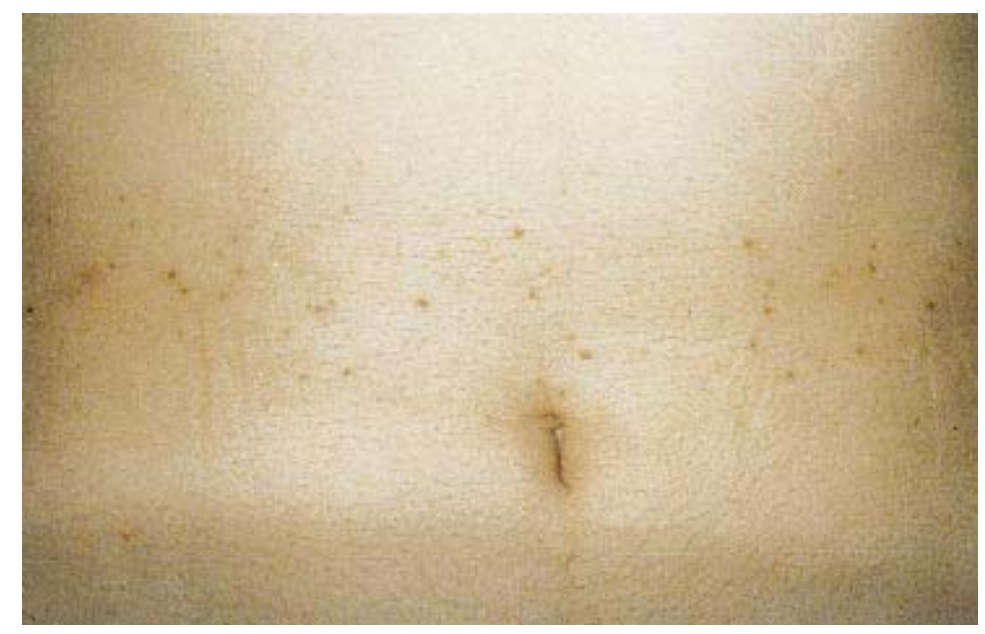

Figure 1. Greyish-brown keratotic lesions forming a band on the anterior wall of the abdomen.

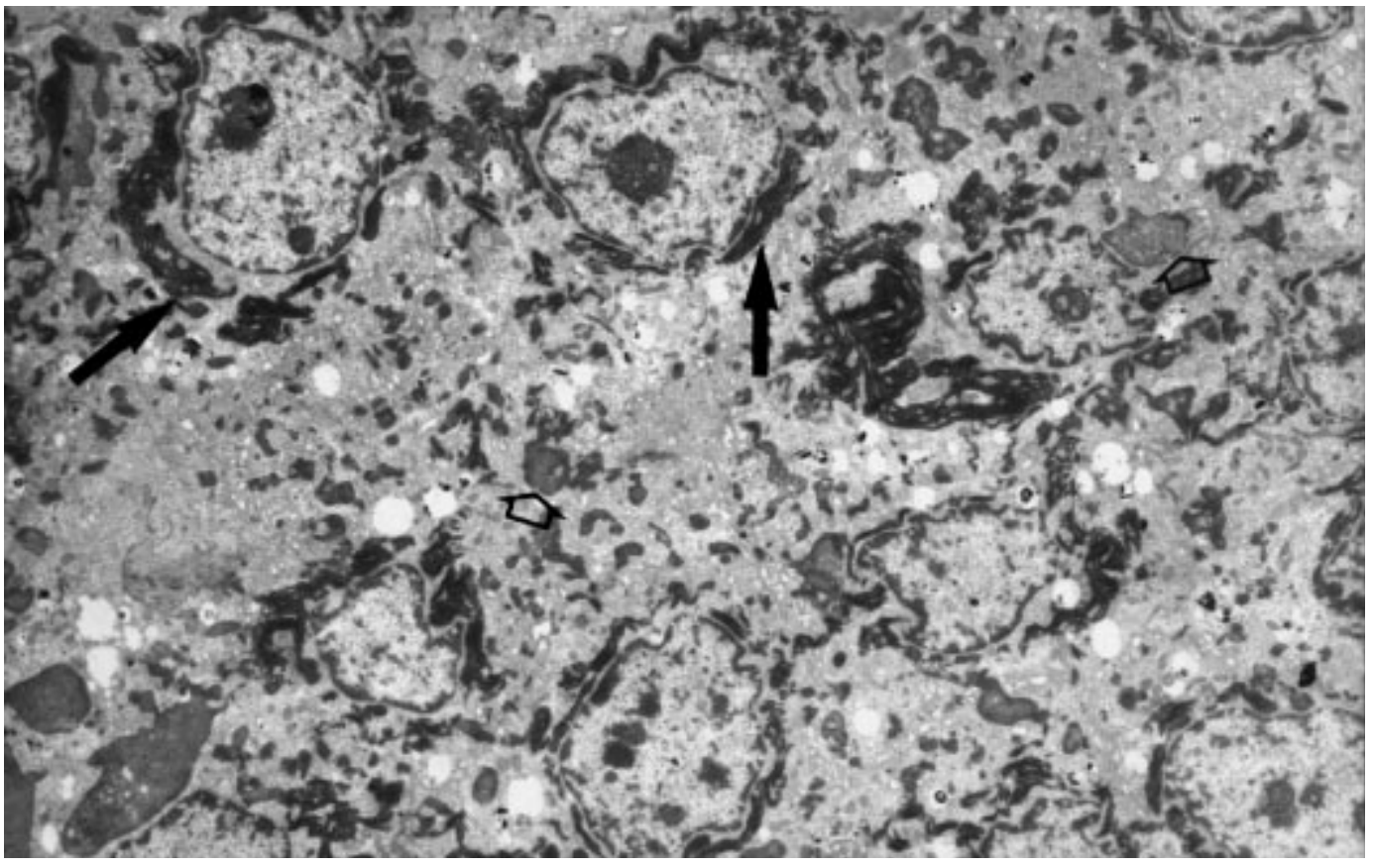

Figure 2. Generalized disorder of the tonofilaments which form two kinds of electrondense masses around the nuclei. Thick bundles of interwoven tonofilaments with partial loss of the fibrillar character; these are very osmiophilic, and are mainly arranged around the nucleus (arrows). Large amorphous masses of variable size and irregular shape, arranged peripherally (hollow arrow). The keratinocytes are apparently cohesive. Note the apparent conservation of the nuclei (original magnification $\times 2475$ ). 


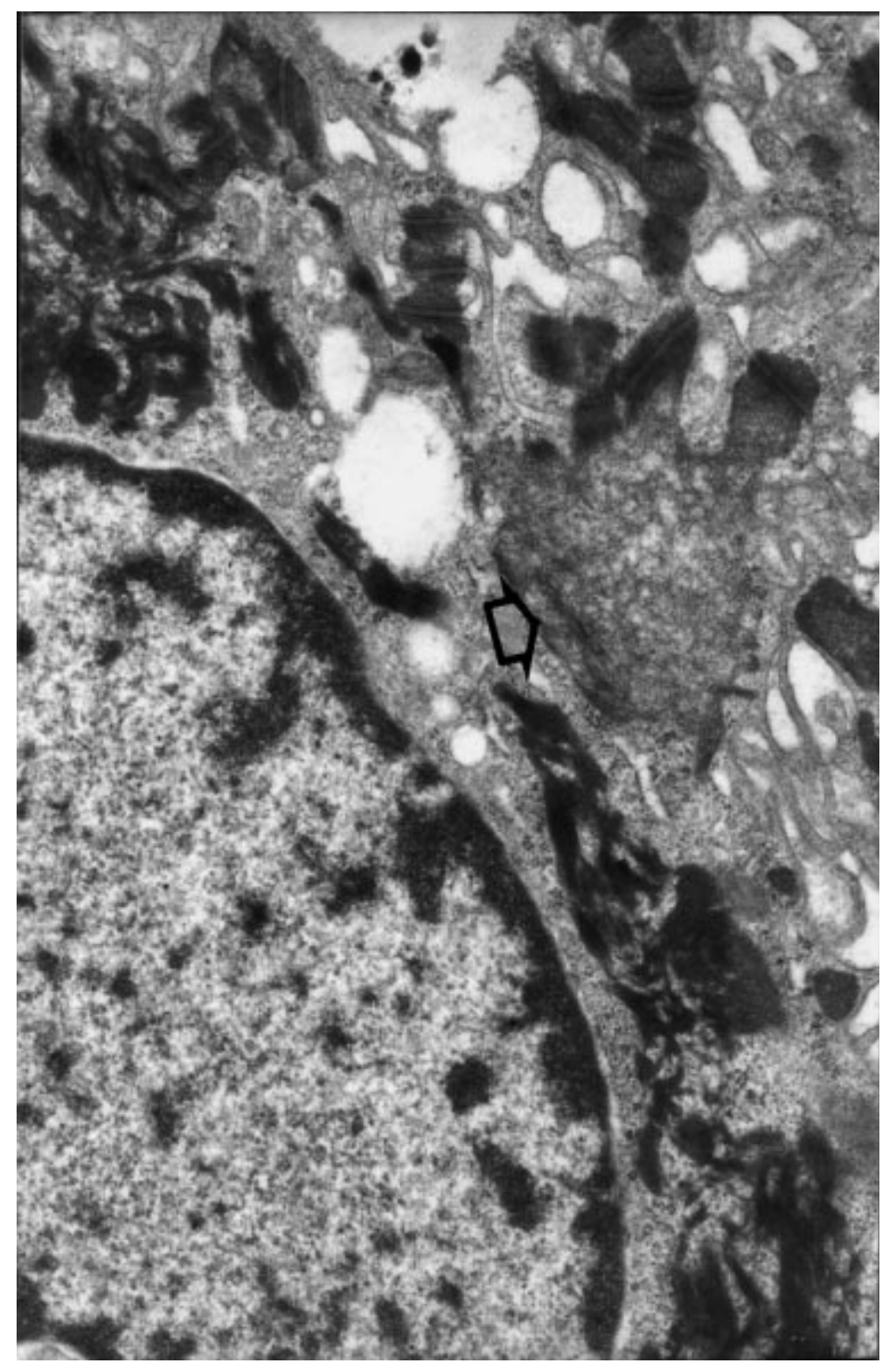

Figure 3. Complete loss of the fascicular nature of the tonofilaments and adoption of a homogeneous granular appearance (arrow head). However, the desmosome has apparent structural integrity (original magnification $\times 15,000$ ). 